\title{
Indel Mutation
}

National Cancer Institute

\section{Source}

National Cancer Institute. Indel Mutation. NCI Thesaurus. Code C99752.

A mutation class that includes insertion mutations, deletion mutations and mutation events where both an insertion and a deletion has occurred. 